\title{
Cross-sectional study of psychiatric comorbidities in patients with atopic dermatitis and nonatopic eczema, urticaria, and psoriasis
}

This article was published in the following Dove Press journal: Neuropsychiatric Disease and Treatment

\author{
Hye-Jin Ahn ${ }^{1, *}$ \\ Min Kyung Shin ${ }^{1, *}$ \\ Jong-Kil Seo' \\ Su Jin Jeong ${ }^{2}$ \\ Ah Rang Cho ${ }^{3}$ \\ Sun-Hee Choi ${ }^{4}$ \\ Bark-Lynn Lew ${ }^{5}$ \\ 'Department of Dermatology, College of \\ Medicine, Kyung Hee University, Seoul, \\ Korea; ${ }^{2}$ Medical Science Research \\ Institute, Kyung Hee University Medical \\ Center, Seoul, Korea; ${ }^{3}$ Department of \\ Psychiatry, Kyung Hee University \\ Hospital at Gangdong, Kyung Hee \\ University School of Medicine, Seoul, \\ Korea; ${ }^{4}$ Department of Pediatrics, Kyung \\ Hee University Hospital at Gangdong, \\ Kyung Hee University School of \\ Medicine, Seoul, Korea; ${ }^{5}$ Department of \\ Dermatology, Kyung Hee University \\ Hospital at Gangdong, Kyung Hee \\ University School of Medicine, Seoul, \\ Korea
}

*These authors contributed equally to this work
Background: Recent data suggest depression has been linked to chronic skin diseases, including atopic dermatitis (AD), urticaria, and psoriasis. This study compared mental illnesses in patients with $\mathrm{AD}$ with those of patients with nonatopic eczema, urticaria, and psoriasis in Korea.

Methods: A cross-sectional study design was used, analyzing data from the 2015 Korean National Health Insurance Research Database, a survey of 42,641 AD and 139,486 non-AD (nonatopic eczema, urticaria, and psoriasis) patients (103,938 males, 78,189 females) classified by age: infant, aged 0-3 years; early childhood, aged 4-8 years; late childhood, aged 9-12 years; adolescent, aged 13-18 years; adult, aged 19-64 years; elderly, aged above 65 years. Multiple logistic regression analysis was performed, and the odds ratio (OR) of various mental illnesses - attention-deficit/hyperactivity disorder (ADHD), autism spectrum disorder (ASD), conduct disorder, depression, anxiety, suicidal ideation, schizophrenia, and sleep disorder - were calculated for patients with and without AD.

Results: The incidence of depression was not significantly different between AD and non$\mathrm{AD}$ patients. Severe $\mathrm{AD}$ showed a high $\mathrm{OR}$ of depression (moderate $\mathrm{AD} \mathrm{OR}=1.75$; severe $\mathrm{AD} \mathrm{OR}=3.15, P<0.0001)$. Patients with $\mathrm{AD}$ had significantly higher incidence of ADHD (OR=1.48; 95\% CI=1.27-1.72), ASD (OR=1.54; 95\% $\mathrm{CI}=1.19-1.99)$, and conduct disorder $(\mathrm{OR}=2.88 ; 95 \% \mathrm{CI}=1.52-5.45)$.

Conclusion: Patients with AD were not found to have higher incidence of depression than non-AD patients. However, severe AD patients were determined to have a significantly higher incidence of depression. Therefore, the severity of dermatitis is thought to contribute to depression. Mental illnesses found to be significantly higher in AD patients were ADHD, ASD, and conduct disorder.

Keywords: atopic dermatitis, Korean National Health Insurance Research Database, mental illness

\section{Introduction}

Atopic dermatitis (AD), a common chronic inflammatory skin disease that may persist into adulthood, is associated with intense pruritus, high rates of sleep disturbance, and poor quality-of-life. ${ }^{1,2}$ The prevalence of AD is $15-20 \%$ among children, and $1-3 \%$ among adults worldwide. ${ }^{3}$ Psychological distress is one of the common comorbidities linked to AD, and could negatively affect quality-of-life. ${ }^{4}$ Previous large-scale population studies have found an association between $\mathrm{AD}$ and mental illnesses. ${ }^{5-8}$ Children with $\mathrm{AD}$ in the US had significantly higher prevalence of attention-deficit/hyperactivity
Department of Dermatology, Kyung Hee University Hospital at Gangdong, Kyung Hee University School of Medicine, \#892, Dongnam-ro, Gangdong-gu, Seoul 05278, Republic of Korea

$\mathrm{Tel}+8224407329$

Fax +822 4407336

Email bellotte@hanmail.net
Neuropsychiatric Disease and Treatment 2019:15 1469-1478

1469 
disorder (ADHD; odds ratio $[\mathrm{OR}]=1.87 ; 95 \%$ confidence interval $[\mathrm{CI}]=1.54-2.27)$, depression $(\mathrm{OR}=1.81 ; 95 \%$ $\mathrm{CI}=1.33-2.46)$, anxiety $(\mathrm{OR}=1.77 ; 95 \% \mathrm{CI}=1.36-2.29)$, conduct disorder $(\mathrm{OR}=1.87 ; 95 \% \mathrm{CI}=1.46-2.39)$, and autism $(\mathrm{OR}=3.04 ; 95 \% \mathrm{CI}=2.13-4.34)$ than those without $\mathrm{AD}^{5}{ }^{5}$ Cheng et $\mathrm{al}^{6}$ found that Taiwanese patients with AD had an elevated risk of developing major depression (MDD) (hazard ratio $[\mathrm{HR}]=6.56 ; 95 \% \mathrm{CI}=3.64-11.84)$, depressive disorders $(\mathrm{HR}=5.44 ; 95 \% \mathrm{CI}=3.99-7.44)$, and anxiety disorders $(\mathrm{HR}=3.57 ; 95 \% \mathrm{CI}=2.55-4.98)$. In Korea, $\mathrm{Kim}$ et $\mathrm{al}^{7}$ found that depressive symptoms were significantly higher in $\mathrm{AD}$ patients than in matched controls. A recent study of adolescents from Korea found slightly increased risks of suicidal ideation, planning, and attempts in patients with $\mathrm{AD}^{8}$ However, these previous studies investigated differences between $\mathrm{AD}$ and normal controls. A wide range of dermatologic disorders, such as $\mathrm{AD}$, psoriasis, and chronic urticaria, have been reported to be associated with depression. ${ }^{9}$ The objective of our study was to perform a comprehensive comparison of mental illnesses in all age groups of patients with $\mathrm{AD}$ and patients with other chronic skin disease through a large population-based survey in Korea.

\section{Materials and methods}

\section{Data source}

A cross-sectional study design was used to analyze the Korean National Health Insurance Research Database for 2015, a survey of 42,641 AD and 139,486 non-AD (non atopic eczema, urticaria, and psoriasis) patients. Medical records were analyzed according to the codes of the International Statistical Classification of Diseases (ICD10). We also investigated data from 2002 to 2014 for past AD (L20.9) diagnostic records. The study was approved by the Institutional Review Board of Kyung Hee University Hospital (KMC IRB 2016-05-406).

\section{Inclusion criteria of patients and classification of data}

We classified patients by age: infant, $0-3$ years; early childhood, 4-8 years; late childhood, 9-12 years; adolescence, 13-18 years; adulthood, 19-64 years; elderly, above 65 years.

Patients with non-AD were considered as those with nonatopic eczema, urticaria (L50.9), or psoriasis (L40.9). Nonatopic eczema included seborrheic dermatitis (L21.9), irritant contact dermatitis (L24.9), and allergic contact dermatitis (L23.9).
It was difficult to classify the severity of $\mathrm{AD}$ using severity scores. Therefore, we divided the group as follows: patients with mild AD included only those receiving topical treatment, patients with moderate $\mathrm{AD}$ were those treated with antihistamines, and severe AD patients were defined as those treated with systemic immunosuppressive therapy. Patients were considered to have a history of $\mathrm{AD}$ if they were diagnosed with $\mathrm{AD}$ at least once between 2002 to 2014.

Mental illnesses included ADHD (F90.0), ASD (autism spectrum disorder) (F84.0), conduct disorder (F91.9), depression (F32.2, F32.8, F32.9), anxiety (F41.9), suicidal ideation (R45.8), schizophrenia (F20.9), and sleep disorder (G47.9).

\section{Statistical analysis}

Multiple logistic regression models were created for each mental illness to control for known confounders that might influence the relationship between $\mathrm{AD}$ and each mental illness. A $P$-value of less than 0.05 was considered statistically significant. All data processing and statistical analyses were performed with IBM SPSS Statistics version 21 (IBM) and SAS version 9.2 (SAS Institute, Cary, NC, USA).

\section{Results}

Overall, 182,127 patients were included in our study: 31,471 infants, 25,227 in early childhood, 14,677 in late childhood, 29,526 adolescents, 67,878 adults, and 13,348 elderly. There were 42,641 patients with AD, 71,699 with nonatopic eczema, 62,464 with urticaria, and 5,323 with psoriasis.

\section{Prevalence rate of mental illnesses in $A D$ and non-AD patients}

We analyzed the frequency of each psychiatric disease in $\mathrm{AD}$ and non-AD patients. We calculated that the prevalence of depression in $\mathrm{AD}$ patients was $2.47 \%$ (Table 1 ).

\section{Mental illnesses according to AD}

In the multiple logistic regression models, there was no significant difference in the prevalence of depression between $\mathrm{AD}$ and non-AD patients (Table 2). Patients with $\mathrm{AD}$ demonstrated increased prevalence of ADHD $(\mathrm{OR}=1.48 ; 95 \% \quad \mathrm{CI}=1.27-1.72), \quad \mathrm{ASD} \quad(\mathrm{OR}=1.54 ; 95 \%$ $\mathrm{CI}=1.19-1.99)$, and conduct disorder $(\mathrm{OR}=2.88 ; 95 \%$ $\mathrm{CI}=1.52-5.45)$, and lower prevalence of anxiety 


\begin{tabular}{|c|c|c|c|c|c|c|c|c|c|c|c|c|c|c|c|c|c|c|c|c|c|c|}
\hline $\begin{array}{l}\frac{\lambda}{\bar{亠}} \\
\frac{0}{\overline{0}}\end{array}$ & $\begin{array}{l}8 \\
\infty \\
+1\end{array}$ & \begin{tabular}{l} 
o \\
\multirow{+}{*}{} \\
-
\end{tabular} & 1 & $\begin{array}{l}\widehat{\tilde{o}} \\
0 \\
\dot{0} \\
m\end{array}$ & I & $\begin{array}{l}\widehat{\overline{0}} \\
\underline{0}\end{array}$ & 1 & $\begin{array}{l}\widehat{\sigma} \\
\stackrel{0}{0} \\
\sim\end{array}$ & 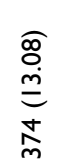 & 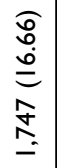 & $\begin{array}{l}\underset{f}{0} \\
\infty \\
\stackrel{\infty}{=} \\
\stackrel{\tilde{n}}{n}\end{array}$ & 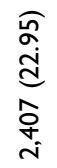 & $\begin{array}{l}\frac{\widehat{m}}{d} \\
\frac{\bar{c}}{\sigma}\end{array}$ & $\begin{array}{l}\hat{0} \\
\stackrel{d}{d} \\
\tilde{J} \\
\text { d. }\end{array}$ & $\begin{array}{l}\widehat{\circ} \\
\stackrel{\circ}{0} \\
\underline{0}\end{array}$ & $\begin{array}{l}\hat{E} \\
\overline{0} \\
\bar{\infty}\end{array}$ & 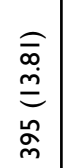 & $\begin{array}{l}0 \\
\frac{0}{N} \\
= \\
\stackrel{0}{0} \\
-\end{array}$ & 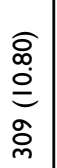 & $\begin{array}{l}\underset{\hat{C}}{\mathfrak{S}} \\
\stackrel{m}{=} \\
\stackrel{m}{m}\end{array}$ & 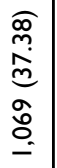 & 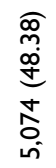 \\
\hline$\frac{\frac{U}{\Xi}}{\frac{\partial}{\alpha}}$ & $\begin{array}{l}\frac{\pi}{\sigma} \\
\dot{\Xi}\end{array}$ & $\begin{array}{l}\text { ठे } \\
\text { î } \\
\text { in }\end{array}$ & 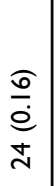 & $\begin{array}{l}\frac{\pi}{0} \\
\stackrel{0}{\infty} \\
\infty\end{array}$ & $\begin{array}{l}\frac{\widehat{m}}{0} \\
\underline{0} \\
\underline{a}\end{array}$ & $\begin{array}{l}\widehat{o} \\
\dot{e} \\
\stackrel{\varphi}{f}\end{array}$ & $\begin{array}{l}\widehat{\sigma} \\
\stackrel{d}{e} \\
\mathrm{~m}\end{array}$ & 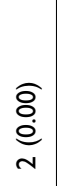 & 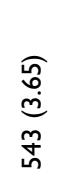 & $\begin{array}{l}\widehat{\bar{N}} \\
\dot{ \pm} \\
\sigma \\
\sigma \\
\dot{d}\end{array}$ & 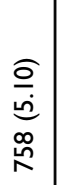 & 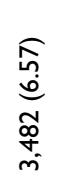 & $\begin{array}{l}\stackrel{f}{f} \\
\stackrel{0}{0} \\
\stackrel{\infty}{0}\end{array}$ & 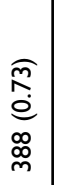 & $\begin{array}{l}\widehat{\widehat{o}} \\
\stackrel{0}{0} \\
\text { o }\end{array}$ & $\begin{array}{l}\widehat{F} \\
\stackrel{0}{0} \\
\bar{f} \\
\bar{j}\end{array}$ & $\begin{array}{l}\widehat{\bar{\sigma}} \\
m \\
\hat{i} \\
\bar{n}\end{array}$ & 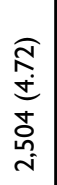 & 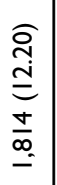 & 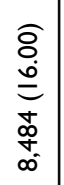 & 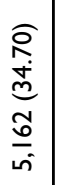 & 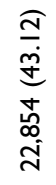 \\
\hline 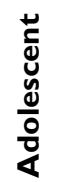 & $\begin{array}{c}\text { m. } \\
\infty_{\infty}^{-}\end{array}$ & $\frac{\hat{\infty}}{\hat{n}}$ & $\begin{array}{l}\widehat{o} \\
\stackrel{\Xi}{=} \\
\hat{\alpha}\end{array}$ & $\begin{array}{l}\text { o. } \\
\text { อे } \\
\text { oे }\end{array}$ & \begin{tabular}{l} 
స్ \\
¿ \\
\multirow{\sim}{\sim}{}
\end{tabular} & $\begin{array}{l}\widehat{\tilde{J}} \\
\tilde{e} \\
\sigma \\
\sigma\end{array}$ & $\begin{array}{l}\frac{\widehat{x}}{0} \\
\underline{0} \\
\underline{0}\end{array}$ & $\begin{array}{l}\widehat{o} \\
\stackrel{0}{c} \\
\underline{m}\end{array}$ & 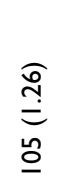 & 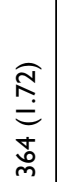 & $\begin{array}{l}\widehat{\bar{m}} \\
\stackrel{\equiv}{=} \\
\text { o }\end{array}$ & 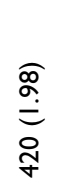 & $\begin{array}{l}\frac{E}{0} \\
\text { d } \\
\underline{t}\end{array}$ & 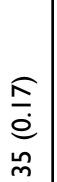 & $\begin{array}{l}\frac{\widehat{m}}{e} \\
= \\
=\end{array}$ & $\begin{array}{l}\widehat{\bar{\tau}} \\
\stackrel{e}{0} \\
\text { J }\end{array}$ & \begin{tabular}{l} 
స్ \\
¿ \\
\multirow{\sim}{N}{}
\end{tabular} & 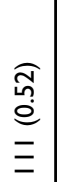 & 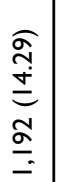 & $\begin{array}{l}\underset{\infty}{0} \\
\stackrel{\infty}{\infty} \\
= \\
\bar{m} \\
\stackrel{\infty}{m}\end{array}$ & 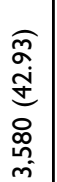 & 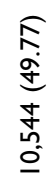 \\
\hline
\end{tabular}

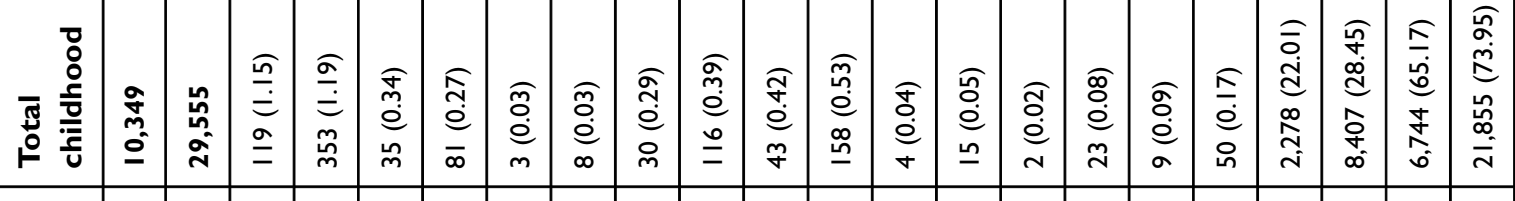

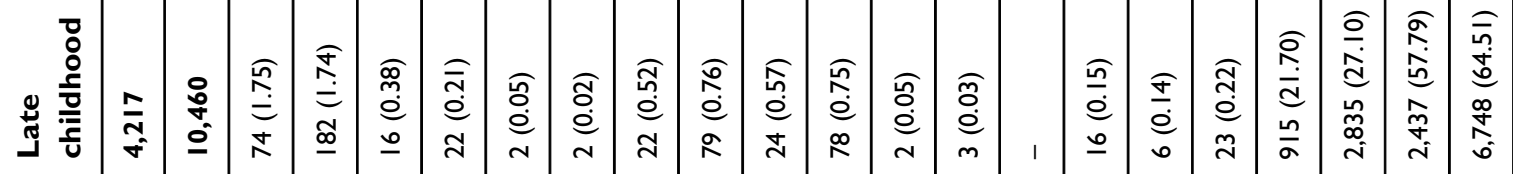

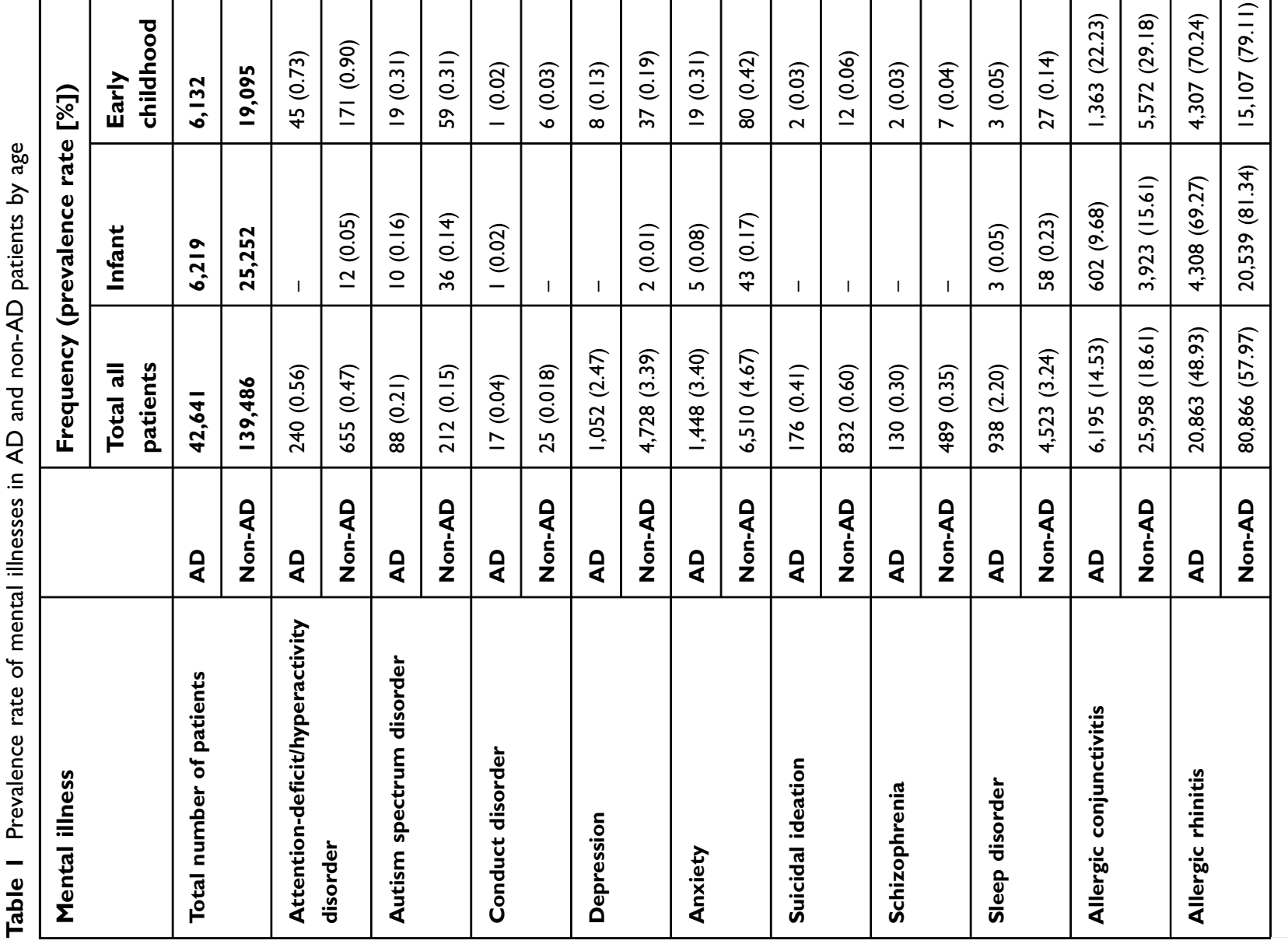




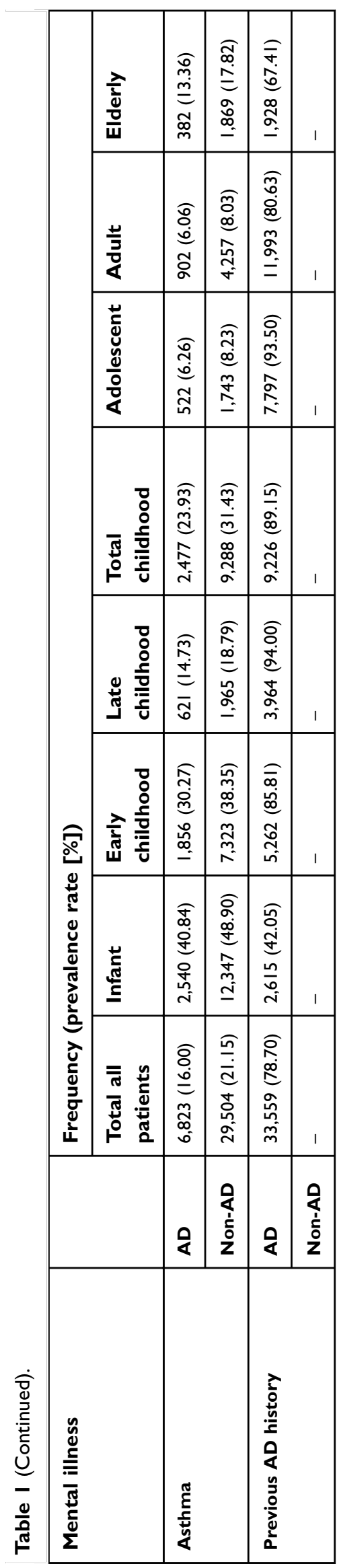

$(\mathrm{OR}=0.91 ; \quad 95 \% \quad \mathrm{CI}=0.85-0.97) \quad$ and $\quad$ sleep disorder $(\mathrm{OR}=0.85 ; 95 \% \mathrm{CI}=0.79-0.92)$ than patients with nonAD. There was no significant difference in schizophrenia or suicidal ideation.

\section{Mental illnesses in AD, urticaria, and psoriasis compared to non-AD eczema}

As shown in Table 3, there was no significant difference in depression between urticaria and $\mathrm{AD}$ patients and nonatopic eczema patients. However, patients with psoriasis showed a higher prevalence of depression ( $\mathrm{OR}=1.38$; 95\% $\mathrm{CI}=1.23-1.56)$. While the results showed that the prevalence of $\mathrm{ADHD}(\mathrm{OR}=1.25 ; 95 \% \mathrm{CI}=1.06-1.48)$ and conduct disorder $(\mathrm{OR}=2.74 ; 95 \% \mathrm{CI}=1.30-5.78)$ increased in patients with AD, there was no significant difference in ASD. Patients with urticaria demonstrated increased prevalence of anxiety $(\mathrm{OR}=1.10 ; 95 \% \mathrm{CI}=1.04-1.16)$, suicidal ideation $(\mathrm{OR}=1.33$; 95\% $\mathrm{CI}=1.15-1.53)$, and sleep disorder $(\mathrm{OR}=1.18 ; 95 \%$ $\mathrm{CI}=1.11-1.26)$. Patients with psoriasis showed an increased prevalence of anxiety $(\mathrm{OR}=1.16 ; 95 \% \mathrm{CI}=1.03-1.30)$, sleep disorder ( $\mathrm{OR}=1.29 ; 95 \% \mathrm{CI}=1.14-1.47)$, and depression. $\mathrm{AD}$ patients did not show significantly different prevalence rates of anxiety, suicidal ideation, or sleep disorder.

\section{Difference in mental illness according to $A D$ severity}

As the severity of $\mathrm{AD}$ increased, the odds of all mental illnesses increased (Table 4). The odds ratio of depression in moderated $\mathrm{AD}$ was $1.75(95 \% \mathrm{CI}=1.42-2.16)$, and in severe $\mathrm{AD}$, it was $3.15(95 \% \mathrm{CI}=2.83-3.51)$. As the severity of $\mathrm{AD}$ increased, the odds of anxiety (moderate $\mathrm{AD}$ $\mathrm{OR}=1.59$; severe $\mathrm{AD} \quad \mathrm{OR}=2.64$ ) and sleep disorder (mild $\mathrm{AD} \mathrm{OR}=0.88$; moderate $\mathrm{AD} \mathrm{OR}=1.31$; severe $\mathrm{AD}$ $\mathrm{OR}=2.56)$ also increased. The prevalence of suicidal ideation $(\mathrm{OR}=2.68,95 \% \mathrm{CI}=2.08-3.46)$ and schizophrenia $(\mathrm{OR}=3.26$; $95 \% \mathrm{CI}=2.40-4.43$ ) was higher in patients with severe AD.

\section{Difference in mental illness according to AD history}

As shown in Table 5, patients with AD history had a higher prevalence of depression $(\mathrm{OR}=1.23 ; 95 \% \mathrm{CI}=1.06-1.44)$ and $\operatorname{ADHD}(\mathrm{OR}=3.56 ; 95 \% \mathrm{CI}=2.21-5.73)$.

\section{Difference in mental illness according to concomitant AD}

AD patients with allergic conjunctivitis (AC) showed a higher prevalence of ADHD $(\mathrm{OR}=1.53 ; 95 \%$ 
Table 2 Multiple logistic regression analysis of mental illnesses and atopic dermatitis (AD) in total patients

\begin{tabular}{|c|c|c|}
\hline \multirow[t]{2}{*}{ Mental illness } & \multicolumn{2}{|l|}{ AD } \\
\hline & $\begin{array}{l}\text { Odds }(95 \% \\
\text { CI) }{ }^{\dagger}\end{array}$ & $P$-value \\
\hline $\begin{array}{l}\text { Attention-deficit/hyperactivity } \\
\text { disorder }^{\mathrm{a}}\end{array}$ & $1.48(1.27 \sim 1.72)$ & $<0.0001$ \\
\hline Autism spectrum disorder ${ }^{\mathrm{a}}$ & $1.54(1.19 \sim 1.99)$ & 0.0010 \\
\hline Conduct disorder $^{a}$ & $2.88(1.52 \sim 5.45)$ & 0.0011 \\
\hline Depression & $0.94(0.88 \sim 1.01)$ & 0.0991 \\
\hline Anxiety & $0.91(0.85 \sim 0.97)$ & 0.0036 \\
\hline Suicidal ideation & $0.90(0.76 \sim 1.06)$ & 0.2143 \\
\hline Schizophrenia & $1.08(0.88 \sim 1.31)$ & 0.4777 \\
\hline Sleep disorder & $0.85(0.79 \sim 0.92)$ & $<0.0001$ \\
\hline
\end{tabular}

Notes: *Adjusted by age, gender, economic status, severity of atopic dermatitis, AD history, concomittent allergic disease. †Odds ratio calculated vs non-AD controls. ${ }^{a}$ Means are significantly different.

$\mathrm{CI}=1.13-2.07)$, and conduct disorder $(\mathrm{OR}=3.02 ; 95 \%$ $\mathrm{CI}=1.07-8.49)$ than $\mathrm{AD}$ patients without AC. Patients with $\mathrm{AD}$ and allergic rhinitis (AR) showed increased anxiety $(\mathrm{OR}=1.15,95 \% \mathrm{CI}=1.02-1.30)$ and sleep disorder $(\mathrm{OR}=1.31 ; 95 \% \mathrm{CI}=1.14-1.52)$ compared to $\mathrm{AD}$ patients without AR (Table 6).

\section{Discussion}

Our study investigated the associations between AD and several mental illnesses across all age groups: children, adults, and the elderly. Chronic skin disorders such as atopic eczema, psoriasis, and chronic urticaria can significantly influence psychological distress. Furthermore, AD is a well-known chronic eczema and is often associated with other atopic disorders, such as AC, AR, and asthma, and major depression is known to be one of the main disorders associated with chronic skin disorders. A psychiatric epidemiological survey by the Ministry of Health and Welfare found that the lifetime prevalence rate of Korean MDD was 5\%, and the period prevalence rate was $1.5 \%$ of the total Korean population in $2016 .{ }^{10}$ We calculated the period prevalence of depression in $\mathrm{AD}$ patients to be $2.47 \%$, which was higher than the overall Korean rate.

There have been a few epidemiological studies on relationships between $\mathrm{AD}$ and psychological distress in children and adults. Some studies reported that patients with $\mathrm{AD}$ have more marked depression than healthy adults, and that patients with more severe $\mathrm{AD}$ are more depressed. ${ }^{11,12}$ Like AD, chronic allergic contact dermatitis affects behavioral and physiological stress. ${ }^{13}$
Seborrheic dermatitis is more prevalent in patients with depression, ${ }^{14}$ and psoriasis and urticaria patients are more likely to have depression. ${ }^{15,16}$ Most of these largepopulation based studies analyzed populations in comparison to a normal control group. We compared prevalence between patients with $\mathrm{AD}$ and non-AD, such as other chronic dermatologic disease (eg, seborrheic dermatitis, irritant or allergic contact dermatitis, urticaria, and psoriasis). Our results showed the prevalence of depression was not significantly different between $A D$ and non-AD patients (Table 2). However, more severe AD showed a higher odds ratio for depression (Table 4). In addition, patients who had a history of $\mathrm{AD}$ had prevalence of depression (Table 5). History of AD could be interpreted as long-term $\mathrm{AD}$ as well as an AD history in infancy or childhood. We suggested that the severity and duration of dermatitis contribute to depression as well as the type of dermatitis.

It has been suggested that some dermatologic patients' depressive symptoms are associated with cosmetic disfigurement and body image problems, and facial involvement has been associated with depressive mood. ${ }^{17,18} \mathrm{~A}$ prior study examining the relationship between pruritus and depression among a group of patients with pruritic skin disorders, including psoriasis, AD, and chronic idiopathic urticaria, found that patients with higher pruritic scores also had higher depression scores. ${ }^{19}$

We conducted a logistic regression analysis of $\mathrm{AD}$, urticaria, and psoriasis separately, with nonatopic eczema as the reference group (Table 3). As a result, although the odds ratio was not high, the prevalence of depression in patients with psoriasis was significantly higher. Gupta and Gupta $^{17}$ examined the prevalence of depression (measured by the Carroll Rating Scale for Depression) among 480 patients, and found that psoriasis and acne were associated with higher depression scores than alopecia areata and AD. Patients with both urticaria and psoriasis had higher prevalence of anxiety and sleep disorder. There was no significant difference in anxiety and sleep disorder prevalence between patients with $\mathrm{AD}$ and nonatopic eczema. However, severe $\mathrm{AD}$ was associated with increased prevalence of both anxiety and sleep disorder (Table 4).

Previous studies on the link between anxiety and AD are controversial. Several studies have reported no significant difference in anxiety levels between $\mathrm{AD}$ patients and normal controls, ${ }^{12}$ and no significant correlation between $\mathrm{AD}$ severity and anxiety. ${ }^{20}$ However, other 
Table 3 Multiple logistic regression analysis of mental illnesses in atopic dermatitis (AD) compared to non-AD eczema, urticaria, and psoriasis

\begin{tabular}{|c|c|c|c|}
\hline Mental illness & Skin disease & Odds $(95 \% \mathrm{Cl})^{\dagger}$ & $P$-value \\
\hline \multirow[t]{3}{*}{ Attention-deficit/hyperactivity disorder } & $A D$ & $1.25(1.06 \sim 1.48)$ & 0.0091 \\
\hline & Urticaria & $0.68(0.58 \sim 0.80)$ & $<0.0001$ \\
\hline & Psoriasis & $0.97(0.64 \sim 1.49)$ & 0.9023 \\
\hline \multirow[t]{3}{*}{ Autism spectrum disorder } & $A D$ & $1.24(0.94 \sim 1.64)$ & 0.1312 \\
\hline & Urticaria & $0.61(0.46 \sim 0.81)$ & 0.0007 \\
\hline & Psoriasis & $0.63(0.26 \sim 1.57)$ & 0.3226 \\
\hline \multirow[t]{3}{*}{ Conduct disorder } & $A D$ & $2.74(1.30 \sim 5.78)$ & 0.0084 \\
\hline & Urticaria & $0.75(0.32 \sim 1.75)$ & 0.4980 \\
\hline & Psoriasis & $3.30(0.91 \sim 11.99)$ & 0.0696 \\
\hline \multirow[t]{3}{*}{ Depression } & $A D$ & $0.96(0.89 \sim 1.04)$ & 0.3401 \\
\hline & Urticaria & $1.01(0.94 \sim 1.07)$ & 0.8664 \\
\hline & Psoriasis & $1.38(1.23 \sim 1.56)$ & $<0.0001$ \\
\hline \multirow[t]{3}{*}{ Anxiety } & $A D$ & $0.96(0.89 \sim 1.03)$ & 0.2056 \\
\hline & Urticaria & $1.10(1.04 \sim 1.16)$ & 0.0012 \\
\hline & Psoriasis & $1.16(1.03 \sim 1.30)$ & 0.0109 \\
\hline \multirow[t]{3}{*}{ Suicidal ideation } & $A D$ & $1.03(0.86 \sim 1.24)$ & $0.752 I$ \\
\hline & Urticaria & $1.33(1.15 \sim 1.53)$ & 0.0001 \\
\hline & Psoriasis & $\mathrm{I} .0 \mathrm{I}(0.74 \sim 1.39)$ & 0.9421 \\
\hline \multirow[t]{3}{*}{ Schizophrenia } & $A D$ & $1.02(0.82 \sim 1.26)$ & 0.8959 \\
\hline & Urticaria & $0.83(0.69 \sim 1.00)$ & 0.0522 \\
\hline & Psoriasis & $1.35(0.96 \sim 1.89)$ & 0.0843 \\
\hline \multirow[t]{3}{*}{ Sleep disorder } & $A D$ & $0.93(0.86 \sim 1.02)$ & 0.1134 \\
\hline & Urticaria & $1.18(1.11 \sim 1.26)$ & $<0.0001$ \\
\hline & Psoriasis & $1.29(1.14 \sim 1.47)$ & $<0.0001$ \\
\hline
\end{tabular}

Notes: Adjusted by age, gender, economic status, severity of atopic dermatitis, AD history, concomittent allergic disease. †Odds ratio calculated vs control group with nonAD eczema.

studies have demonstrated that patients with $\mathrm{AD}$ are more likely to have anxiety than healthy individuals. ${ }^{5,6}$ In addition, a recent large population-based study showed that moderate-to-severe AD was significantly associated with an increased risk of anxiolytic (HR=1.66; 95\% $\mathrm{CI}=1.56-1.77)$ and antidepressant drug use (HR=1.24; 95\% $\mathrm{CI}=1.16-1.31$ ), while patients with mild $\mathrm{AD}$ only had a slightly increased risk of anxiolytic drug use $(\mathrm{HR}=1.08 ; 95 \% \mathrm{CI}=1.01-1.16) .{ }^{21}$

Previous studies have demonstrated that children in the US with $\mathrm{AD}$ have higher prevalence of ADHD, autism, and conduct disorder than unaffected peers. ${ }^{5}$ Our results showed that $\mathrm{AD}$ patients have higher prevalence of ADHD, ASD, and conduct disorder than non-AD patients. These mental illnesses could have more specific implications, such as a genetic relationship with AD.

The mechanisms underlying mental illnesses and $\mathrm{AD}$ are unknown. One of the theoretical mechanisms explaining the association between mental illness and $\mathrm{AD}$ is the chronic nature of the skin disease. Mental illnesses could be a common end result of many chronic disorders, including $\mathrm{AD}$. Blackman et $\mathrm{al}^{22}$ found that children with 
Table 4 Risk of mental illnesses according to atopic dermatitis (AD) severity

\begin{tabular}{|c|c|c|c|}
\hline Mental illness & AD severity & Odds $(95 \% \mathrm{Cl})^{\dagger}$ & $P$-value \\
\hline \multirow[t]{3}{*}{ Attention-deficit/hyperactivity disorder } & Mild & I.I $4(0.84 \sim 1.56)$ & 0.3909 \\
\hline & Moderate & $1.23(0.66 \sim 2.28)$ & 0.5108 \\
\hline & Severe $^{\mathrm{a}}$ & $3.22(2.36 \sim 4.40)$ & $<0.0001$ \\
\hline \multirow[t]{3}{*}{ Autism spectrum disorder } & Mild & $1.07(0.66 \sim 1.74)$ & 0.7872 \\
\hline & Moderate & $0.96(0.33 \sim 2.84)$ & 0.9438 \\
\hline & Severe $^{\mathrm{a}}$ & $2.54(\mathrm{I} .54 \sim 4.2 \mathrm{I})$ & 0.0003 \\
\hline \multirow[t]{3}{*}{ Conduct disorder } & Mild & $0.82(0.23 \sim 2.89)$ & 0.7527 \\
\hline & Moderate & $<0.001(<0.001 \sim>999.999)$ & 0.9809 \\
\hline & Severe & $4.32(1.23 \sim 15.10)$ & 0.0221 \\
\hline \multirow[t]{3}{*}{ Depression } & Mild & $0.92(0.82 \sim 1.03)$ & 0.1515 \\
\hline & Moderate $^{a}$ & $1.75(1.42 \sim 2.16)$ & $<0.0001$ \\
\hline & Severe $^{a}$ & $3.15(2.83 \sim 3.51)$ & $<0.0001$ \\
\hline \multirow[t]{3}{*}{ Anxiety } & Mild & $0.93(0.84 \sim 1.02)$ & 0.1190 \\
\hline & Moderate $^{a}$ & 1.59 (1.32 1.91) & $<0.0001$ \\
\hline & Severe $^{a}$ & $2.64(2.4 \mid \sim 2.88)$ & $<0.0001$ \\
\hline \multirow[t]{3}{*}{ Suicidal ideation } & Mild & $0.98(0.75 \sim 1.28)$ & 0.8558 \\
\hline & Moderate & $1.22(0.70 \sim 2.14)$ & 0.4877 \\
\hline & Severe $^{\mathrm{a}}$ & $2.68(2.08 \sim 3.46)$ & $<0.0001$ \\
\hline \multirow[t]{3}{*}{ Schizophrenia } & Mild & $0.81(0.59 \sim 1.12)$ & 0.2081 \\
\hline & Moderate & $0.73(0.33 \sim 1.62)$ & 0.4367 \\
\hline & Severe $^{a}$ & $3.26(2.40 \sim 4.43)$ & $<0.0001$ \\
\hline \multirow[t]{3}{*}{ Sleep disorder } & Mild $^{\mathrm{a}}$ & $0.88(0.78 \sim 0.98)$ & 0.0237 \\
\hline & Moderate $^{a}$ & 1.31 (1.03 1.67) & 0.0267 \\
\hline & Severe $^{a}$ & $2.56(2.30 \sim 2.85)$ & $<0.0001$ \\
\hline
\end{tabular}

Notes: *Adjusted by age, gender, economic status, AD history, concomittent allergic disease. †Odds ratio calculated vs non-AD controls. ${ }^{a}$ Means are significantly different.

any chronic illness had an increased risk of emotional and behavioral problems, including ADHD. However, in our results, the prevalence rates of $\mathrm{ADHD}, \mathrm{ASD}$, and conduct disorder were significantly higher in $\mathrm{AD}$ than in other chronic skin diseases. Studies have observed increased levels of pro-inflammatory cytokines in $\mathrm{AD}$, and increased cytokines could lead to depression, anxiety, and autism. ${ }^{23,24}$ Schmitt et $\mathrm{al}^{25}$ suggested that the sustained overexpression of inflammatory mediators released during atopic responses could affect the brain circuits associated with ADHD, making children vulnerable to ADHD symptoms. Both $\mathrm{AD}$ and ADHD have complex genetic susceptibility and environmental factors that precipitate into disease manifestation. Several candidate genes encoding major elements of the immune system and proteins involved in the regulation of Th1/Th2 cell differentiation and effector function for atopic traits have been identified. ${ }^{26}$ In particular, genetic variants in the gene encoding signal transducer and activator of transcription 6 (Stat6), a key regulatory element of Th2 immune response, have been associated with atopy-related traits. ${ }^{27,28}$ Stat6 is also highly expressed in the central nervous system and is suggested to play a major role in ADHD pathogenesis. ${ }^{29}$ In addition, previous research on the association between atopy and behavioral symptoms in twins has 
Table 5 Risk of mental illnesses according to atopic dermatitis (AD) history in AD patients

\begin{tabular}{|l|l|l|}
\hline Mental illness & \multicolumn{1}{|l|}{ Past AD history } \\
\cline { 2 - 3 } & Odds (95\% CI) & P-value \\
\hline Attention-deficit/hyperactivity disorder & $<0.0001$ \\
Autism spectrum disorder & $3.56(2.21 \sim 5.73)$ & $0.135 \mathrm{I}$ \\
Conduct disorder & $1.55(0.87 \sim 2.74)$ & 0.3437 \\
Depression & $2.06(0.46 \sim 9.22)$ & 0.0072 \\
Anxiety & $1.23(1.06 \sim 1.44)$ & 0.0797 \\
Suicidal ideation & $1.12(0.99 \sim 1.28)$ & 0.2293 \\
Schizophrenia & $0.82(0.59 \sim 1.14)$ & 0.1195 \\
Sleep disorder & $0.74(0.50 \sim 1.08)$ & 0.4133 \\
\hline
\end{tabular}

Notes: ${ }^{a}$ Adjusted by age, gender, economic status, severity of atopic dermatitis, concomittent allergic diseases: Means are significantly different. ${ }_{\dagger}$ Odds ratio calculated vs control group with no history of atopic dermatitis.

Table 6 Risk of mental illnesses according to concomitant atopic disease in atopic dermatitis (AD) patients

\begin{tabular}{|l|l|l|l|l|l|l|}
\hline \multirow{2}{*}{ Mental illness } & \multicolumn{2}{l|}{ Allergic conjunctivitis } & \multicolumn{2}{l|}{ Allergic rhinitis } & \multicolumn{2}{l|}{ Asthma } \\
\cline { 2 - 7 } & Odds (95\% CI) & P-value & Odds (95\% CI) & P-value & Odds (95\% CI) & $P$-value \\
\hline Attention-deficit/hyperactivity & $1.53(I .13 \sim 2.07)$ & 0.0063 & $1.21(0.91 \sim 1.60)$ & 0.2009 & $0.44(0.30 \sim 0.65)$ & $<0.000 \mathrm{I}$ \\
disorder & & & & & \\
Autism spectrum disorder & $1.14(0.66 \sim 1.99)$ & 0.6383 & $0.75(0.47 \sim 1.20)$ & 0.2280 & $0.54(0.30 \sim 1.00)$ & 0.0502 \\
Conduct disorder & $3.02(1.07 \sim 8.49)$ & 0.0363 & $0.38(0.13 \sim 1.12)$ & 0.0796 & $1.13(0.32 \sim 4.01)$ & 0.8546 \\
Depression & $1.00(0.83 \sim 1.20)$ & 0.9943 & $0.92(0.80 \sim 1.05)$ & 0.2272 & $0.67(0.55 \sim 0.83)$ & 0.0002 \\
Anxiety & $1.12(0.95 \sim 1.31)$ & 0.1729 & $1.15(1.02 \sim 1.30)$ & 0.0187 & $0.97(0.82 \sim 1.14)$ & 0.6732 \\
Suicidal ideation & $0.70(0.43 \sim 1.15)$ & 0.1571 & $1.10(0.80 \sim 1.52)$ & 0.5497 & $1.03(0.66 \sim 1.59)$ & 0.9124 \\
Schizophrenia & $0.74(0.42 \sim 1.31)$ & 0.3031 & $0.63(0.43 \sim 0.93)$ & 0.0188 & $0.50(0.26 \sim 0.95)$ & 0.0355 \\
Sleep disorder & $1.10(0.91 \sim 1.34)$ & 0.3331 & $1.31(1.14 \sim 1.52)$ & 0.0002 & $0.92(0.75 \sim 1.13)$ & 0.4021 \\
\hline
\end{tabular}

Notes: Adjusted by age, gender, economic status, severity of atopic dermatitis, AD history, †Odds ratio calculated vs. control group with non-AD eczema.

supported the hypothesis of shared genetic factors influencing the risk for atopic and behavioral disorders. ${ }^{30}$

We investigated whether AC, AR, or asthma increased mental illnesses in $\mathrm{AD}$ patients. The results showed that AC was more associated with the prevalence of ADHD and conduct disorder than $\mathrm{AD}$ alone. $\mathrm{AR}$ was associated with an increased prevalence of anxiety and sleep disorder. However, asthma was associated with lower prevalence of ADHD and depression. Prior studies have suggested a link between allergies and ADHD. A meta-analysis showed a stronger association between children with ADHD and asthma than control groups. For $\mathrm{AR}, \mathrm{AD}$, and $\mathrm{AC}$, the odds were slightly higher in children with ADHD than in children without ADHD. ${ }^{31}$ Cheng et $\mathrm{al}^{6}$ revealed that AR associated with $\mathrm{AD}$ resulted in a higher risk of depressive disorders and anxiety disorders than in the absence of AR. Further studies may be needed to explain the comorbidity of atopic disease and mental illnesses.
In conclusion, although the prevalence of depression was higher in patients with $\mathrm{AD}$ than in the overall Korean population, there was no significant difference in the prevalence between $\mathrm{AD}$ and non-AD patients. However, the severity and history of $\mathrm{AD}$ were closely related to the prevalence of depression. The presence of AD was associated with higher prevalence of ADHD, ASD, and conduct disorder than nonatopic dermatologic disease. Further studies are required to investigate the underlying disease mechanisms between $\mathrm{AD}$ and these mental illnesses.

\section{Ethics}

The data accessed is anonymized.

\section{Approval}

The Institutional Review Board of the Kyung Hee University Hospital has approved the study (KMC IRB 2016-05-406). 


\section{Acknowledgments}

This paper was presented at the 2018 American Academy of Dermatology Conference as a poster presentation with interim findings. The poster's abstract was published in "Poster Abstracts" in the Journal of the American Academy of Dermatology. This study received funding from the Korean Atopic Dermatitis Association.

\section{Disclosure}

The authors report no conflicts of interest in this work.

\section{References}

1. Silverberg JI, Garg NK, Paller AS, Fishbein AB, Zee PC. Sleep disturbances in adults with eczema are associated with impaired overall health: a US population-based study. $J$ Invest Dermatol. 2015;135:56-66. doi:10.1038/jid.2014.325

2. Kim JP, Chao LX, Simpson EL, Silverberg JI. Persistence of atopic dermatitis (AD): a systematic review and meta-analysis. $J$ Am Acad Dermatol. 2016;75:681-7.e11. doi:10.1016/j.jaad.2016.05.028

3. Asher MI, Montefort S, Bjorksten B, et al. Worldwide time trends in the prevalence of symptoms of asthma, allergic rhinoconjunctivitis, and eczema in childhood: ISAAC phases one and three repeat multicountry crosssectional surveys. Lancet. 2006;368:733-743. doi:10.1016/S0140-6736(06)69283-0

4. Wittkowski A, Richards HL, Griffiths CE, et al. The impact of psychological and clinical factors on quality of life in individuals with atopic dermatitis. $J$ Psychosom Res. 2004;57:195-200 doi:10.1016/j.jpsychores.2004.04.371

5. Yaghmaie P, Koudelka CW, Simpson EL. Mental health comorbidity in patients with atopic dermatitis. $J$ Allergy Clin Immunol. 2013;131:428-433. doi:10.1016/j.jaci.2012.10.041

6. Cheng CM, Hsu JW, Huang KL, et al. Risk of developing major depressive disorder and anxiety disorders among adolescents and adults with atopic dermatitis: a nationwide longitudinal study. J Affect Disord. 2015;178:60-65. doi:10.1016/j.jad.2015.02.025

7. Kim S, Lee JY, Oh JY, Chekal L, Lee DC. The association between atopic dermatitis and depressive symptoms in Korean adults: the fifth Korea national health and nutrition examination survey, 2007-2012. Korean J Fam Med. 2015;36:261-265. doi:10.4082/kjfm.2015.36.6.261

8. Lee S, Shin A. Association of atopic dermatitis with depressive symptoms and suicidal behaviors among adolescents in Korea: the 2013 Korean youth risk behavior survey. BMC Psychiatry. 2017;17:3 doi:10.1186/s12888-017-1489-6

9. Gupta MA, Gupta AK. The use of antidepressant drugs in dermatology. J Eur Acad Dermatol Venereol. 2001;15:512-518. doi:10.1046/j.1468-3083.2001.00278.x

10. Korean Ministry of Health and Welfare. [The Report on Epidemiology of Mental Illnesses]; 2017. Available from: http://www.mohw.go.kr/react/jb/ sjb030301vw.jsp?PAR_MENU_ID=03\&MENU_ID $=032901 \& C O N T$ _ $\mathrm{SEQ}=339138 \&$ page $=1$. Accessed May 7, 2019. Korean.

11. Arima M, Shimizu Y, Sowa J, et al. Psychosomatic analysis of atopic dermatitis using a psychological test. J Dermatol. 2005;32:160-168. doi:10.1111/j.1346-8138.2005.tb00738.x

12. Hashiro M, Okumura M. Anxiety, depression and psychosomatic symptoms in patients with atopic dermatitis: comparison with normal controls and among groups of different degrees of severity. J Dermatol Sci. 1997;14:63-67. doi:10.1016/S0923-1811(96)00553-1
13. Kitagaki H, Hiyama H, Kitazawa T, Shiohara T. Psychological stress with long-standing allergic dermatitis causes psychodermatological conditions in mice. $J$ Invest Dermatol. 2014;134:1561-1569. doi:10.1038/jid.2014.31

14. Maietta G, Fornaro P, Rongioletti F, Rebora A. Patients with mood depression have a high prevalence of seborrhoeic dermatitis. Acta Derm Venereol. 1990;70:432-434.

15. Dowlatshahi EA, Wakkee M, Arends LR, Nijsten T. The prevalence and odds of depressive symptoms and clinical depression in psoriasis patients: a systematic review and meta-analysis. $J$ Invest Dermatol. 2014;134:1542-1551. doi:10.1038/jid.2013.508

16. Engin B, Uguz F, Yilmaz E, Ozdemir M, Mevlitoglu I. The levels of depression, anxiety and quality of life in patients with chronic idiopathic urticaria. J Eur Acad Dermatol Venereol. 2008;22:36-40. doi:10.1111/j.1468-3083.2007.02324.x

17. Gupta MA, Gupta AK. Depression and suicidal ideation in dermatology patients with acne, alopecia areata, atopic dermatitis and psoriasis. Br J Dermatol. 1998;139:846-850.

18. Klokk M, Gotestam KG, Mykletun A. Factors accounting for the association between anxiety and depression, and eczema: the Hordaland health study (HUSK). BMC Dermatol. 2010;10:3. doi:10.1186/1471-5945-10-3

19. Gupta MA, Gupta AK, Schork NJ, Ellis CN. Depression modulates pruritus perception: a study of pruritus in psoriasis, atopic dermatitis, and chronic idiopathic urticaria. Psychosom Med. 1994;56:36-40.

20. Linnet J, Jemec GB. An assessment of anxiety and dermatology life quality in patients with atopic dermatitis. $\mathrm{Br} J$ Dermatol. 1999;140:268-272. doi:10.1046/j.1365-2133.1999.02661.x

21. Thyssen JP, Hamann CR, Linneberg A, et al. Atopic dermatitis is associated with anxiety, depression, and suicidal ideation, but not with hospitalization or suicide. Allergy. 2017. doi:10.1111/ all.13231

22. Blackman JA, Gurka MJ, Gurka KK, Oliver MN. Emotional, developmental and behavioural co-morbidities of children with chronic health conditions. J Paediatr Child Health. 2011;47:742-747. doi:10.1111/j.1440-1754.2011.02044.x

23. Pollak Y, Yirmiya R. Cytokine-induced changes in mood and behaviour: implications for depression due to a general medical condition', immunotherapy and antidepressive treatment. Int J Neuropsychopharmacol. 2002;5:389-399. doi:10.1017/S1461145702003152

24. Zimmerman AW, Jyonouchi H, Comi AM, et al. Cerebrospinal fluid and serum markers of inflammation in autism. Pediatr Neurol. 2005;33:195-201. doi:10.1016/j.pediatrneurol.2005.03.014

25. Schmitt J, Buske-Kirschbaum A, Roessner V. Is atopic disease a risk factor for attention-deficit/hyperactivity disorder? A systematic review. Allergy. 2010;65:1506-1524. doi:10.1111/all.2010.65.issue-12

26. Holloway JW, Holgate ST. Genetics of allergic disease. J Allergy Clin Immunol. 2010;125:S81-S94. doi:10.1016/j.jaci.2009.10.071

27. Vercelli D. Discovering susceptibility genes for asthma and allergy. Nat Rev Immunol. 2008;8:169-182. doi:10.1038/nri2257

28. Lau M, Tsantikos E, Maxwell MJ, Tarlinton DM, Anderson GP, Hibbs ML. Loss of STAT6 promotes autoimmune disease and atopy on a susceptible genetic background. J Autoimmun. 2012;39:388-397. doi:10.1016/j.jaut.2012.06.003

29. Yukawa K, Kishino M, Goda M, et al. STAT6 deficiency inhibits tubulointerstitial fibrosis in obstructive nephropathy. Int $\mathrm{J} \mathrm{Mol} \mathrm{Med.}$ 2005;15:225-230.

30. Thomsen SF, Kyvik KO, Backer V. Etiological relationships in atopy: a review of twin studies. Twin Res Hum Genet. 2008;11:1112-1120. doi:10.1375/twin.11.2.112

31. Miyazaki C, Koyama M, Ota E, et al. Allergic diseases in children with attention deficit hyperactivity disorder: a systematic review and meta-analysis. BMC Psychiatry. 2017;17:120. doi:10.1186/s12888017-1489-6 


\section{Publish your work in this journal}

Neuropsychiatric Disease and Treatment is an international, peerreviewed journal of clinical therapeutics and pharmacology focusing on concise rapid reporting of clinical or pre-clinical studies on a range of neuropsychiatric and neurological disorders. This journal is indexed on PubMed Central, the 'PsycINFO' database and CAS, and is the official journal of The International Neuropsychiatric Association (INA). The manuscript management system is completely online and includes a very quick and fair peer-review system, which is all easy to use. Visit http://www.dovepress.com/testimonials.php to read real quotes from published authors. 